\title{
O papel da Internet na constituição de redes sociais transnacionais de sociabilidade e mobilização dos estudantes brasileiros no ensino superior em Portugal The role of Internet in the constitution of transnational social networks of sociability and mobilization of Brazilian students in higher education in Portugal
}

Juliana Chatti Iorio

Doutoranda pelo Programa de Pós-Graduação em Geografia Humana da Universidade de Lisboa, Portugal. E-mail: juioriobr@hotmail.com

Maria Lucinda Cruz dos Santos Fonseca

Doutora pelo Programa de Pós-Graduação em Geografia Humana da Universidade de Lisboa, Portugal. E-mail: fonsecamaria@campus.ul.pt

\section{Resumo:}

Na era da globalização, o papel da Internet tem sido fundamental para a formação de redes de contatos além-fronteiras. Com a introdução das chamadas redes sociais online de relacionamento (Facebook, Twitter, Instagram, Google+, Youtube, MySpace, Badoo, etc), a facilidade em comunicar e obter informações de qualquer parte do globo aumentou ainda mais, apesar do acesso a essas novas mídias ainda não ser igual para todos.

Tendo como base as entrevistas qualitativas realizadas no âmbito do projeto de doutorado em desenvolvimento sobre as trajetórias de mobilidade dos estudantes brasileiros no ensino superior em Portugal, pretende-se discorrer sobre a importância do Facebook na constituição de redes de contatos entre Brasil e Portugal. Os resultados preliminares têm apontado esta rede social online como uma das grandes facilitadoras deste tipo de mobilidade.

\section{Palavras-chave:}

Mobilidade Estudantil Internacional; Brasil; Portugal; Redes Sociais; Novas Tecnologias da Informação e da Comunicação.

\begin{abstract}
:
In the era of globalization, the role of Internet has been essential for the formation of cross-border social networks. With the introduction of social networks (such as Facebook, Twitter, Instagram, Google+, Youtube, MySpace, Badoo, etc), the ease to communicate and receive information from anywhere on earth has increased significantly, despite the fact that the access to these new media is not the same for all the people.

Based on qualitative interviews conducted within the $\mathrm{PhD}$ project in development about the trajectories of mobility of Brazilian students in higher education in
\end{abstract}


Portugal, it is intended to discuss the importance of Facebook in the establishment of social networks between Brazil and Portugal. Preliminary results have indicated this mentioned social network as one of the crucial tools in the process of facilitating such mobility.

\section{Keywords:}

International Student Mobility; Brazil; Portugal; Social Networks; New Technologies of Information and Communication.

\section{Introdução}

Qual o impacto dos meios de comunicação (mídias) digitais na mobilidade estudantil internacional?

As novas Tecnologias da Informação e da Comunicação (TICs), com os seus constantes avanços, têm possibilitado que as pessoas se relacionem através da Internet, constituindo redes transnacionais de contatos, que poderão contribuir para a sociabilidade e a mobilização das mesmas. No caso dos estudantes brasileiros que encontram-se no ensino superior, as redes de contato estabelecidas por meio de redes sociais online, com indivíduos que estão em outros países (sejam estes brasileiros ou estrangeiros), muitas vezes funcionam como uma fonte privilegiada de informação, que poderá contribuir para a sociabilidade desses estudantes no país de destino.

Sabe-se que, no campo da educação, a globalização tem permitido, entre outras coisas, uma maior integração da pesquisa científica mundial, fazendo expandir o mercado de trabalho internacional, o que, pode-se concluir, tem fomentado, cada vez mais, a necessidade de se ter uma experiência de mobilidade estudantil internacional. Ou seja, atualmente, os estudantes estão bem conscientes da importância de se ter uma experiência de mobilidade internacional como "prova de mérito", e da necessidade de construírem redes transnacionais de colaboração, participando no sistema global de produção e troca de conhecimento (DELICADO, 2008; MAZZA, 2008; VIDEIRA, 2013).

Por isso, antes mesmo de se estabelecer redes transnacionais científicas, a ideia da mobilidade estudantil internacional pode começar a se materializar por meio do estabelecimento de redes sociais (com familiares, amigos e/ou conhecidos), fomentada ainda mais pelo uso de mídias digitais, como a Internet. É nas chamadas 
"Redes Sociais Online" que, por fim, poderão estabelecer-se os contatos decisivos para a prossecução deste tipo de mobilidade e, posteriormente, para a sociabilidade do "Estudante-Migrante" ${ }^{1 "}$ no país de destino.

É sabido que as conexões/os laços pessoais/o estabelecimento de redes sociais com os migrantes pioneiros, fornecem aos futuros migrantes os recursos necessários para se diminuir os riscos e os custos da migração (VERTOVEC, 2002; BROOKS; WATERS, 2010; DE HAAS, 2010). Com o "Estudante-Migrante" passa-se o mesmo, apesar destes confiarem mais nas redes estabelecidas com os seus "pares" e, por isso, serem mais seletivos no estabelecimento destes contatos. Daí a importância das "Comunidades/ Grupos" criadas em determinadas redes sociais online, onde se partilham informações de interesse comum à maior parte dos seus participantes. Como já haviam referido Oiarzabal e Reips (2012), por meio da Internet tornou-se muito mais fácil e rápido o acesso a grupos específicos, onde os usuários podem escolher, seletivamente, as comunidades com base nos seus interesses.

Mas até que ponto a Internet, por meio de redes sociais online, contribui para a formação de redes transnacionais de mobilização e sociabilidade dos estudantes brasileiros em Portugal?

De acordo com uma pesquisa realizada pelo Instituto Brasileiro de Opinião Pública e Estatística (IBOPE), por meio dos dados do Censo Demográfico Brasileiro de 2010 e da Pesquisa Nacional por Amostra de Domicílio (PNAD) de 2011, do Instituto Brasileiro de Geografia e Estatística (IBGE) ${ }^{2}$, sabe-se que o acesso à Internet no Brasil ainda é desigual e que a renda familiar e a escolaridade continuam a criar um "hiato digital" entre quem é um cidadão conectado e quem não é. Os elementos geracionais ou etários também mostraram que os jovens são os usuários mais intensos destas novas mídias e o recorte por escolaridade indicou que $87 \%$ dos respondentes com ensino superior costumam acessar a Internet pelo menos uma vez

\footnotetext{
${ }^{1}$ Consideraremos aqui a definição das Nações Unidas (1998) de que "a migração internacional de um indivíduo implica que este se mude do seu país de residência atual para outro, por um período entre três meses a um ano (migração de curta duração) ou superior a um ano (migração de longa duração)" (VIDEIRA, 2013, p. 139). Logo, o estudante internacional ou móvel, definido pela Organização para a Cooperação e Desenvolvimento Econômico (OCDE) como aquele que deixou o seu país de origem e mudou-se para outro país para fins de estudo (Education at a Glance 2014: OECD Indicators), será aqui considerado um Estudante-Migrante.

2 Informação disponível em: http://www.secom.gov.br/atuacao/pesquisa/lista-de-pesquisasquantitativas-e-qualitativas-de-contratos-atuais/pesquisa-brasileira-de-midia-pbm-2015.pdf. Acesso em: $15 / 01 / 2016$.
} 
por semana. Entre as redes sociais online mais utilizadas o Facebook destacou-se em primeiro lugar com $83 \%$ da preferência.

Portanto, considerando que o estudante brasileiro do ensino superior é um usuário da Internet, e tendo em conta que as entrevistas realizadas para o projeto de doutorado em desenvolvimento confirmaram o Facebook como uma das redes sociais online mais utilizadas, pretende-se responder às seguintes questões de investigação:

1 - Podem as conexões estabelecidas por meio do Facebook influenciar a escolha de Portugal como país de destino?

2 - Podem as redes sociais estabelecidas por meio do Facebook contribuir para a sociabilidade destes estudantes com outros do país de origem e com estrangeiros?

3 - Os laços estabelecidos a partir desta rede social online podem ser considerados fortes?

Para responder a essas perguntas, tomou-se por base 52 entrevistas semiestruturadas realizadas aos estudantes brasileiros que estão, ou já estiveram, estudando em Portugal, analisando as respostas sobre o tópico "Comunicação/Informação", com referência às informações que estes estudantes obtiveram sobre o país, a cidade e a instituição de destino antes de emigrarem, e como se deu o acesso a essas informações.

Por meio do método da "Bola de Neve", entrevistou-se estudantes com diferentes perfis (provenientes da graduação, mestrado e doutorado; de diferentes regiões do Brasil; e que se dirigiram, maioritariamente, para as regiões de Lisboa, Porto e Coimbra - as que mais têm recebido estudantes de nacionalidade brasileira em Portugal). A maioria das entrevistas foi realizada presencialmente, num local previamente agendado pelo estudante, e teve, em média, uma hora de duração. Posteriormente procedeu-se a transcrição integral e a análise das mesmas. Vale salientar que uma das ferramentas utilizadas para se chegar a esses estudantes foi o próprio Facebook. Por meio da divulgação da pesquisa em "Comunidades/Grupos" nesta rede social online, conseguiu-se aceder aos mais variados grupos de estudantes brasileiros no ensino superior português.

Sabe-se, porém, que o tipo de amostragem utilizada não pode ser considerada representativa, apesar da disponibilidade dos estudantes para participarem nesta 
pesquisa, talvez em parte devido ao fato da nacionalidade do entrevistador ser a mesma do entrevistado, ter gerado uma certa "cumplicidade", um certo "à vontade", responsável pela maioria das respostas ter sido dada sem reservas e com frontalidade. Acredita-se, portanto, na fiabilidade dos resultados obtidos e no fato de que a análise dos mesmos, confrontados com os conceitos teóricos utilizados, fornece, preliminarmente, apontamentos que poderão ser utilizados em estudos futuros.

Assim, o texto que se segue está estruturado em quatro pontos fundamentais:

- O primeiro aborda a influência das novas Tecnologias da Informação e da Comunicação na mobilidade internacional dos estudantes universitários no século $\mathrm{XXI}$;

- O segundo faz uma breve contextualização da evolução da mobilidade internacional dos estudantes brasileiros do ensino superior para Portugal;

- O terceiro analisa os resultados da investigação empírica que sustenta o estudo;

- O quarto apresenta algumas notas conclusivas.

\section{A influência das novas Tecnologias da Informação e da Comunicação na Mobilidade Estudantil Internacional do Século XXI}

O século XXI é considerado um século de fluidez e abertura, em que as mudanças nas tecnologias, nos transportes e na cultura fizeram com que as pessoas passassem a considerar "normal" pensar "além-fronteiras". Assim, movimentos com o propósito de estudo, profissionalização, casamento, aposentadoria ou simplesmente mudança de estilo de vida assumiram uma relevância maior (CASTELLS, 2010).

Em entrevista ao jornal português "Público", de 6 de janeiro de 2016, o professor do Departamento de Filosofia da Universidade Nova de Lisboa, Diogo Pires Aurélio (2010), afirmou que:

[...] os novos meios de comunicação aproximaram as pessoas. À imagem do metrô, com as pessoas a consultarem os e-mails, posso contrapor a das famílias, todos os fins de semana, a contactarem com os filhos e netos que vivem nos Estados Unidos, em Berlim ou na Tailândia [...] as formas de 
comunicação alteraram-se, não só em termos de grau, mas da forma como se processam. (AURÉLIO, 2010) ${ }^{3}$.

No entanto, para este mesmo professor, não há dúvidas de que a pesquisa científica que se faz hoje é diferente: "Basta olharmos para as grandes bibliotecas que têm tido, tendencialmente, todo o seu espólio, sobre o qual não recaem direitos de autor, digitalizado.” Salt, em 1997, já defendia esta posição dizendo que as novas TICs poderiam reduzir a migração internacional dos que ele chamou de "altamente qualificados", visto que o conhecimento poderia ser transferido, de outras maneiras que não implicassem, necessariamente, a presença física.

Mas, se por um lado, os novos meios de comunicação vieram facilitar a investigação à distância, por outro lado, são esses mesmos meios que estão aguçando, cada vez mais, a vontade e a curiosidade de estudantes e pesquisadores em irem estudar no exterior.

Com o uso cada vez mais generalizado da Internet - ainda que, na visão de Papacharissi (2009), continue restrito a um grupo seleto de pessoas ${ }^{4}$ - os indivíduos que fornecem informações por meio deste meio podem ter um papel crucial na migração (VAN MEETEREN; PEREIRA, 2013). Deste modo, pode-se dizer que a difusão digital global veio facilitar certos aspectos da mobilidade estudantil internacional, visto que hoje, entre o grupo dos estudantes universitários, o uso da Internet é cada vez mais comum, e por meio dela é muito mais fácil obter informações e ter acesso às opiniões sobre as universidades, faculdades e cursos no exterior.

Vale, no entanto, salientar que isto refere-se apenas aos desembaraços que as novas TICs trouxeram para este tipo de mobilidade, facilitando a divulgação e o acesso a determinados conteúdos, e não à qualidade dos mesmos, que pode ser questionada.

\footnotetext{
${ }^{3}$ Entrevista realizada por Nuno Ribeiro, "Órgãos de comunicação enfraquecem quando vão a jogo com as redes sociais", Jornal Público, Portugal, Edição de 6 de Janeiro de 2016. Informação disponível em: <https://www.publico.pt/politica/noticia/liberdade-de-informacao-orgaos-decomunicacao-perdem-quando-vao-a-jogo-com-as-redes-sociais-1719244>. Acesso em: 06/01/2016.

${ }^{4} \mathrm{E}$, dependendo do continente, restrito a um grupo bem pequeno de indivíduos, visto que, segundo Papacharissi, em 2009, a difusão digital global apresentava-se da seguinte forma: América do Norte: 70\%, Oceânia: 54\%, Europa: 39\%, Ásia: 10,7\%, África: 3,6\%, América Latina: 17,3\% e Médio Oriente: $10 \%$.
} 
Além disso, uma maior facilidade no acesso aos meios de transportes necessários para a realização deste tipo de mobilidade também fez aumentar a procura pelo estudo no exterior, ampliando a concorrência, e, consequentemente, diminuindo os custos deste tipo de migração. Como já havia referido Cairncross apud Dekker e Engbersen, "A 'morte da distância' foi reduzindo os custos e diminuindo os riscos de migração" (2012, p. 402).

O fato é que a migração dos altamente qualificados não foi reduzida, como previu Salt em 1997, e cada vez mais os migrantes criam e/ou participam de sites, blogs, páginas pessoais, comunidades/grupos em redes sociais online, para falar de suas experiências migratórias. E, neste aspeto, o estudante-migrante não é diferente. Nesta apropriação da Internet, esse estudante também cria espaços de interação e conversação que, "tende a homogeneizar e diluir as singularidades e imprevisibilidades que constituem as experiências migratórias contemporâneas" (MEZZADRA apud COGO, 2014, p. 92).

Faist, em 2010, baseando-se na "Força dos Laços Fracos" de Granovetter (1973), referiu que as aspirações individuais, sociais, políticas e econômicas, que influenciam a decisão de migrar, podem ser conectadas pelas redes sociais e pelo capital social de cada indivíduo. Nessas redes, os "laços fortes" são aqueles caracterizados pelo contato cara-a-cara dos atores envolvidos, em contrapartida aos "laços fracos", caracterizados por relações indiretas (amigos de amigos, por exemplo). Se transportarmos para o contexto das redes sociais online, pode-se considerar "fortes" os laços já existentes entre as pessoas fora do ambiente digital (e que podem se prolongar nesta esfera) e "fracos" aqueles que se estabelecem com desconhecidos através desse meio. Assim, ao construir e/ou participar de "espaços online" com desconhecidos, o estudante-migrante consegue ativar o seu capital social $^{5}$ e criar ou inserir-se em redes de apoio e sociabilidade, que poderão ajudá-lo

\footnotetext{
${ }^{5}$ Capital Social é "o total dos recursos reais ou potenciais que estão ligados à posse de uma rede durável de relações, mais ou menos institucionalizadas, de conhecimento mútuo ou reconhecimento". (BOURDIEU apud DEKKER; ENGBERSEN, 2002, p. 403). A maioria dos estudiosos da migração entende estas redes como um conjunto de "laços fortes", baseados no parentesco, amizade ou numa comunidade compartilhada de origem que "liga" os migrantes e não migrantes. No entanto, o que se tem observado é que muitas pessoas não pertencem a esta tradicional, coesa e delimitada comunidade, mas se movem dentro e fora de diversas comunidades, criando "laços fracos" que podem ser úteis na coleta de informações e recursos (DEKKER; ENGBERSEN., Op. Cit.). Isto, por sua vez, poderá vir a incrementar o capital social dessas pessoas.
} 
no planejamento e implementação do seu projeto migratório, e contribuir para a sua integração no país de destino.

Pode-se, entretanto, argumentar que qualquer outro grupo de usuários de uma rede social online, e não somente os estudantes e/ou migrantes, pode criar espaços de interação e conversação nessa esfera virtual, facilitando não só a mobilidade estudantil internacional, mas qualquer outro tipo de experiência contemporânea. Este argumento, no entanto, não menciona que, antes de mais, este grupo deve ter acesso à Internet. Sabe-se, porém, que o acesso à Internet não contempla todos os grupos sociais e que, por isso, "as vantagens da Internet podem ser apreciadas apenas pelo grupo seleto de pessoas que tiver acesso à ela" (PAPACHARISSI, 2002, p. 9). No caso específico dos brasileiros, viu-se que são os jovens, maioritariamente com ensino superior, que formam este grupo seleto que acede a Internet pelo menos uma vez por semana, e têm o Facebook como rede social online preferida. Logo, deste grupo, aqueles que quiserem realizar uma mobilidade estudantil internacional serão, tendencialmente, mais propensos à utilizar o Facebook como meio de informação e de comunicação.

Assim, não se pode falar que "qualquer grupo de usuários de uma rede social online" pode construir e/ou participar nesses espaços, já que, também na esfera virtual reproduzem-se os privilégios de classes e as desigualdades sociais presentes na esfera pública (PAPACHARISSI, 2002).

\section{Estudantes Brasileiros no Ensino Superior em Portugal}

A mobilidade das chamadas "elites" brasileiras para Portugal verifica-se desde o período colonial, quando entre 1577 e 1822, a Universidade de Coimbra licenciou 2.464 estudantes (em Direito) oriundos dessas "elites" " No entanto, é só no chamado "Mundo Moderno" que a emigração de brasileiros para Portugal acontece com maior pujança. Nos séculos XIX e XX são os brasileiros com maior qualificação que emigram para Portugal em busca de um melhor posicionamento no mercado de

\footnotetext{
${ }^{6}$ Enciclopédia Barsa, vol. 5, 1989, p. 391 apud RUZON, B. P. Filhos de Coimbra. Uma história do ensino jurídico brasileiro. Jus Navigandi, Teresina, Ano 10, No.1201, outubro 2006. Disponível em: $<$ http://jus2.uol.com.br/doutrina/texto.asp?id=9039>. Acesso em: 15/10/2011.
}

INTERIN, v. 22, n. 1, jan./jun. 2017. ISSN: 1980-5276. 
trabalho, e na viragem do século $\mathrm{XX}$ são os brasileiros menos qualificados que passam a ocupar o setor primário em Portugal (MALHEIROS, 2007). Mas é a partir dos anos 90 que se começa a verificar um aumento no interesse de acadêmicos e pesquisadores brasileiros por Portugal, nos vários ramos do saber, e nas várias universidades espalhadas pelo território nacional (ROCHA, 2010).

Pode-se atribuir este aumento a diversos fatores:

Em 2001 é firmado o "Tratado de Amizade, Cooperação e Consulta entre a República Federativa do Brasil e a República Portuguesa", estabelecendo a cooperação no domínio do ensino e da pesquisa (com o reconhecimento de graus e títulos acadêmicos e de especialização obtidos em instituições de ensino superior de ambos os países);

Em 2004 é assinado um acordo que prevê a criação de um "Espaço de Ensino Superior da CPLP ${ }^{7}$, , demostrando o interesse dos Estados-membros numa cooperação multilateral;

Em 2007, a nova lei da imigração em Portugal passa a ser mais específica em relação às condições de entrada e permanência dos estudantes internacionais no país.

Assim, no ano letivo de $2008 / 2009^{8}$, verifica-se que a comunidade de estudantes brasileiros do ensino superior ${ }^{9}$ passa a ser a maior de estudantes internacionais em Portugal $(3813)^{10}$.

Após 2008, o número destes estudantes continua a aumentar, estimulado, entre outras coisas, pelo contínuo investimento público realizado em pesquisa e desenvolvimento no Brasil:

Em 2010, a Coordenação de Aperfeiçoamento do Ensino Superior (CAPES), com base no Tratado de Amizade referido acima e no Memorando de Entendimento assinado entre esta Instituição e a Universidade de Coimbra, cria o Programa de

\footnotetext{
${ }^{7}$ Comunidade dos Países de Língua Portuguesa.

${ }^{8} \mathrm{O}$ ano letivo em Portugal tem início por volta do dia 10 de Setembro e acaba em finais de Julho do ano seguinte.

${ }^{9}$ Os estudantes do ensino superior em Portugal são abrangidos pelo ensino universitário e politécnico. O ensino universitário é ministrado em instituições universitárias (públicas e privadas) e o politécnico em instituições de ensino superior não universitárias (também públicas e privadas). Os graus de licenciado e mestre são conferidos tanto pelas universidades, como pelos politécnicos. O grau de doutor é conferido somente pelas universidades. Assim, neste estudo considerarei os inscritos num dos três ciclos de estudo do ensino superior português: licenciatura (graduação), mestrado ou doutorado.

10 Informação disponível em: <http://www.dgeec.mec.pt/np4/EstatVagasInsc/>. Acesso em: 06/05/2013.
} 
Licenciaturas Internacionais (PLI), que em 2012 e 2013 é alargado a outras universidades portuguesas;

Em 2011, o Governo Federal brasileiro lança o Programa Ciência sem Fronteiras (CsF), que, em vigor ainda hoje, procura "promover a consolidação, expansão e internacionalização da ciência e tecnologia, da inovação e da competitividade brasileira por meio do intercâmbio e da mobilidade internacional ${ }^{11}$ ".

Apesar de em abril de 2013 Portugal ter passado a não fazer mais parte do edital deste Programa, "por não estimular o aprendizado de um novo idioma"12, o contingente de estudantes brasileiros no ensino superior português, no ano letivo de 2014/2015, continuava a ser o maior do país (7.356 em um universo de 29.039 estudantes internacionais $)^{13}$, o que leva a crer que, além das políticas de incentivo à migração estudantil, outros fatores continuaram a estimular este tipo de migração brasileira para Portugal.

Pelo lado de Portugal, tem-se adotado algumas estratégias para a captação destes estudantes. Os estatutos e planos estratégicos das universidades portuguesas referem a mobilidade acadêmica internacional como uma parte essencial das mesmas, e, neste sentido, têm procurado fomentar acordos e parcerias universitárias, reforçando: as relações pessoais e o estabelecimento de redes de contatos, a divulgação online, a participação em eventos internacionais e as publicações no Brasil.

Muitas universidades portuguesas já aceitam alunos aprovados por meio do Exame Nacional de Ensino Médio (ENEM) brasileiro, e têm apostado numa comunicação online mais "agressiva", com páginas de sites dedicadas exclusivamente a estes estudantes, e páginas em redes sociais online ${ }^{14}$, como o Facebook.

Observa-se, assim, que são vários os fatores que têm contribuído para o aumento da mobilidade do estudante brasileiro no ensino superior português. Às

\footnotetext{
${ }^{11}$ Informação disponível em: <http://www.cienciasemfronteiras.gov.br>. Acesso em: 03-06-2014.

${ }^{12}$ Informação disponível em: <http://veja.abril.com.br/noticia/educacao/dilma-promete-mais100000bolsas-no-ciencia-sem-fronteiras $>$. Acesso em: 14/08/2014.

13 Informação disponível em: <http://www.dgeec.mec.pt/np4/EstatVagasInsc/>. Acesso em: 02/08/2016.

${ }^{14}$ Sobre as estratégias de atração das Universidades em Portugal ver: FONSECA, et.al. International Mobility of Brazilian Students to Portugal: the Role of the Brazilian Government and University Strategies in Portugal. Global Change and Human Mobility, Springer, 2016.
}

INTERIN, v. 22, n. 1, jan./jun. 2017. ISSN: 1980-5276. 
redes sociais estabelecidas, que com a introdução das novas TICs incrementaram-se por meio do uso de redes sociais online, juntam-se os fatores de caráter individual (como o idioma, por exemplo), bem como os de ordem política, econômica e social.

\section{A influência do Facebook na mobilização e sociabilidade dos estudantes brasileiros no ensino superior português}

Nas entrevistas efetuadas aos estudantes brasileiros no ensino superior português, procurou-se saber de que forma eles haviam obtido informações sobre o país:

- Onde foram buscar as informações;

- Se utilizaram mídias online (sites, blogs, jornais e/ou revistas online);

- Se utilizaram redes sociais online (Facebook/ Orkut/ Twiter/ Linkedin/ Outras); - Se utilizaram algum motor de busca.

Como era de se esperar, todos os entrevistados disseram utilizar as mídias online para obter informações, mesmo porque as candidaturas às universidades estrangeiras e às bolsas de estudo financiadas por instituições brasileiras ou estrangeiras, se faz, maioritariamente, pela Internet.

Os sites das universidades e blogs, com experiências de pessoas que já haviam vivido em Portugal, foram os mais procurados, e o motor de busca mais utilizado foi o Google.

Dependendo da época em que chegaram em Portugal, as redes sociais online mais utilizadas dividiram-se entre o extinto Orkut e o atual Facebook.

Num primeiro momento, o estudante brasileiro procura as informações sobre o país e a instituição de ensino por meio da Internet, utilizando, maioritariamente, o motor de busca Google, onde tem acesso aos blogs de pessoas que já tiveram uma experiência semelhante e aos sites das instituições de ensino em Portugal. É a partir daí que o estudante começa a acionar as suas redes sociais (com familiares, amigos e/ou conhecidos), mobilizando ou reativando o seu próprio capital social, para obter as primeiras informações sobre o país, a instituição e o curso que pretende frequentar. Estabelece-se, então, um “diálogo" via e-mail, telefone, Skype ou redes 
sociais online que, num segundo momento, pode prolongar-se por meio da participação em comunidades/grupos de interesse presentes no Facebook:

[...] quando a gente viu que estava decidido, a gente começou a pesquisar sistematicamente, até em sites de supermercados para saber os preços [...] Depois, essa parte de acomodação, a gente foi pelo Facebook, a gente encontrou "Grupos de Acomodação" [...]. (J, Évora, 2014 Intercâmbio na Graduação).

No entanto, como a maioria dos entrevistados não conhecia ninguém que já estivesse em Portugal antes da sua migração, a procura por estes contatos só começa a ganhar força após a confirmação desta mobilidade. Assim, como referiu Brookers e Waters (2010), com o intuito de reduzir o caráter individualista da migração, e, como completou De Hass (2010), diminuir os custos inerentes à ela, estes indivíduos recorrem aos seus recursos (capital social, cultural, linguístico e financeiro) para ativarem as redes sociais (que, em princípio, podem ser online).

Quanto às informações que pesquisavam sobre Portugal, a cidade e a instituição de destino, algumas das mais procuradas via redes sociais online prendiam-se, como já referido, com a necessidade de encontrar um local para morar:

[...] eu lançava no Facebook, perguntava "alguém já fechou casa?" “alguém conhece algum lugar pra dividir aluguel?" Eram grupos que a galera pegava e montava "Ciência sem Fronteiras - Lisboa" e aí ia lá, perguntava se tinha arrumado casa, se tinha conseguido, qual que era o bairro mais indicado [...]. (Y, Lisboa, 2012 - Intercâmbio na Graduação).

Portanto, com as redes sociais online ativadas, o estudante começa a estabelecer contatos que poderão, posteriormente, transformar-se em redes de sociabilidade no país de acolhimento:

[...] aí eu perguntei sobre moradia (nesse grupo de brasileiros no Facebook), ela (a menina com quem eu moro hoje) respondeu, e aí a gente começou a conversar [...] Esse grupo de brasileiros no Facebook é um grupo muito unido. O pessoal se encontra pra sair, tomar cerveja junto, muitos dão dicas [...]. (LU, Coimbra, 2014 - Intercâmbio na Graduação).

$\mathrm{Eu}$ procurei alguns grupos e estudantes brasileiros em Portugal no Facebook e aí eu conheci um pessoal antes, um pessoal que faz transfers, uns passeios, a "VIVAP", aí eu combinei e eles foram me pegar de carro lá, foram pegar mais uma galera no aeroporto [...] inclusive a maior parte de amigos que eu tenho aqui são de conhecidos das pessoas que eu

INTERIN, v. 22, n. 1, jan./jun. 2017. ISSN: 1980-5276. 
conheci no aeroporto [...] As comunidades (no Facebook) dão essa integração do estudante muito mais extensa do que a faculdade daqui ou de lá, ou qualquer outro canal [...]. (M, Porto, 2015 - Intercâmbio da Graduação).

Tais contatos, iniciados ainda no Brasil, podem não só perdurar durante a estadia em Portugal, mas também permanecerem após o regresso ao Brasil:

[...] (Ainda no Brasil) eu cheguei a postar se tinha algum estudante de pós-graduação em Portugal, na minha página do Facebook, e apareceu. Inclusive uma que hoje eu ainda tenho contato lá, foi através disso. (CA, Lisboa, 2010 - Doutorado-Sanduíche).

Mesmo os estudantes que não participaram de nenhuma comunidade/grupo no Facebook antes de emigrarem (a maioria porque na época ainda não havia ou não era comum a utilização desta rede), reconheceram a importância da mesma e afirmaram hoje participar, pois além de os auxiliar na partilha de informações, proporciona-lhes uma inserção na vida social da cidade onde vivem:

[...] eu não fazia uso de nenhuma rede social [...] (Mas hoje) Eu tenho um grupo no Facebook que chama "Brasileiros em Coimbra" e lá tem sempre alguém postando "ah, eu tô indo pra Coimbra, como é que faz [...]" ou seja, tudo aquilo que eu não tive, quando eu vim, esse grupo agora faz. (G, Coimbra, 2008 - Mestrado-Pleno - hoje está no DoutoradoPleno).

Você chegou a buscar algum tipo de informação por meio das redes sociais?

Não.

(Mas hoje) A gente tem um grupo no Facebook que chama "Núcleo Lisboa" [...] tem estudantes, trabalhadores, e não só brasileiros, mas acho que na sua maioria sim. Então, por conta do "Núcleo Lisboa", eu sempre tenho coisas para fazer! (N, Coimbra, 2009 - Doutorado-Pleno).

Quando você veio, você não chegou a procurar nada pela Internet?

Naquela época a Internet era só aquela Internet discada, nem tinha computador, laptop...

(Mas hoje) A gente tem um grupo no Facebook, o "BRASUP”, então ali qualquer tipo de informação como, como é que eu chego no Estádio do Dragão, por exemplo, as pessoas colocam lá [...] Por acaso esses grupos são muito úteis. Eu vejo que as pessoas antes de vir perguntam muitas coisas lá também! No "BRASUP" o pessoal está sempre perguntando coisas do SEF, sobre apartamentos, tudo [...] e isso facilita muito [...]. (CR, Porto, veio em 2008, pela primeira vez, para fazer o MestradoPleno. Voltou em 2011 para fazer o Doutorado-Pleno). 
Desta forma, como referiu Faist (2010), os "laços fracos", caracterizados pelas relações indiretas (hoje muito mais facilitadas pelas novas TICs), podem transformar-se em "laços fortes", representados pelas relações diretas (cara-a-cara), de onde podem emergir relações de companheirismo e até de amizade:

\footnotetext{
[...] eu encontrei essa casa na Internet $[\ldots]$ por meio de um grupo do Facebook "Alojamento Universitário" [...] eu entrei em contato com o "J" (que é o dono da casa onde o estudante foi morar), e ele começou a me falar do Porto, porque ele é nascido e criado aqui [...] Foi o primeiro contato que eu tive com a cultura portuguesa. A casa dele é completamente multicultural! Tem pessoas do mundo inteiro [...] Quando eu cheguei morava um português, um argentino, um tanzaniano e dois tchecos [...] E ele que me introduziu em grupos do Facebook daqui, para eu começar a me habituar com a linguagem daqui, com as coisas daqui, porque por mais que a língua seja próxima existe uma diferença, uma barreira linguística e cultural, e eu comecei a me acostumar logo de lá [...] Eu fiz amizade pelo Facebook, já conversava por Skype com o pessoal da casa [...] O convívio que eu tive com eles depois, foi uma das melhores coisas para conhecer o Porto e Portugal. (AL, Porto, 2014 Doutorado-Sanduíche).
}

Apesar do entrevistado acima ter participado em grupos, que por não serem direcionados aos brasileiros, possibilitou uma interação social com portugueses e indivíduos de outras nacionalidades, a maioria dos entrevistados referiu participar em grupos/ comunidades de brasileiros ("Brasileiros em Coimbra", "Brasileiros na Universidade do Porto - BRASUP", etc). Nesses grupos, criados e "frequentados" quase que exclusivamente por brasileiros, dificilmente há interação social com portugueses e/ou indivíduos de outras nacionalidades. Normalmente, os portugueses que lá se encontram utilizam estas comunidades para publicitarem quartos ou casas que têm para alugar, e são poucos os indivíduos de outras nacionalidades que lá participam, pois a "exigência" em se comunicar em língua portuguesa nem sempre está ao alcance de todos. Neste sentido, a constituição destas redes sociais online acaba por conduzir a um certo isolamento da comunidade brasileira universitária, promovendo, por um lado, uma integração entre os nacionais do país de origem no país de destino, mas tendendo a deixar de fora os nativos e indivíduos de outras nacionalidades.

Contudo, mesmo os estudantes mais "resistentes", afirmaram ter descoberto os benefícios do Facebook após emigrarem, apontando esta rede social online como uma necessidade para este tipo de migração: 


\begin{abstract}
Antes de vir, até pouco tempo antes de vir, eu era uma pessoa extremamente resistente com as redes sociais (online). Eu descobri a beleza das redes sociais em Portugal. Hoje eu sou um fã incondicional, acho que o mundo se descobre ali [...] depois que eu cheguei aqui eu descobri uma comunidade de doutorado-sanduíche que tem no Facebook que, se eu tivesse descoberto antes, teria facilitado muito a minha vida. Lá tudo é tratado, tem muita gente que pergunta coisa de Portugal e as pessoas trocam informações de como funciona. (RO, Lisboa, 2014, Doutorado-Sanduíche)
\end{abstract}

[...] depois que eu cheguei, que uma colega lá do alojamento me falou do BRASUP, que era um grupo no Face, ela me explicou. Mas eu só estou lá. Eu acho que é bom, ajuda bastante [...] lá também eu postei que eu fazia brigadeiros (para vender) e teve retorno. (RA, Porto, 2014, Mestrado-Pleno).

\title{
5 Notas conclusivas
}

Os resultados do estudo empírico efetuado, apesar de não poderem generalizar-se ao conjunto dos estudantes brasileiros no ensino superior em Portugal, indicam que as redes sociais, fortalecidas por meio do uso de redes sociais online, como o Facebook, têm influenciado significativamente a mobilidade, na medida em que ajudam a minimizar os temores do desconhecido. Por isso, as experiências daqueles que já se encontram no país de destino acabam por contar mais do que as informações obtidas institucionalmente. Ou seja, como referem Brooks e Waters, "as relações sociais continuam a ser muito importantes, mas os contatos cara-a-cara têm sido menos visíveis do que no passado" (2010, p. 149).

Neste sentido, as mídias digitais têm desempenhado um papel fundamental no imaginário que se forma deste "novo" mundo, visto que são os portadores das informações e das experiências vividas pelos membros dessas redes. Obviamente este artigo refere-se a membros "privilegiados", não "excluídos digitalmente", que conseguem inserir-se nessas redes pois são capazes de ativarem ou reativarem os seus capitais sociais. São migrantes que utilizam a Internet como recurso cotidiano para desenvolverem, manterem e recriarem redes transnacionais formais e informais, tanto no mundo digital, quanto no mundo físico, ao mesmo tempo em que reforçam e moldam os seus sensos de identidade individual e coletiva (OIARZABAL; REIPS, 2012). 
Contudo, não se pode dizer que os meios de comunicação digitais, particularmente a Internet e as redes sociais online, sejam os responsáveis pela migração dos estudantes brasileiros do ensino superior para Portugal, ou seja, pela escolha de Portugal como país de destino. Como já havia referido De Hass (2010), as redes sociais (estabelecidas via mídias digitais ou não ${ }^{15}$ ) facilitam a migração se os membros dessas redes tiverem acesso aos recursos necessários para que essa migração se materialize. Tais recursos não têm que ser, necessariamente, financeiros. A posse de um outro idioma, por exemplo, pode ser um"recurso" necessário para que o estudante consiga emigrar para um país falante deste outro idioma. Em contrapartida, a falta desse "recurso" pode ditar a escolha por Portugal.

De qualquer forma, o estudo empírico efetuado confirma que, munidos destes "recursos", e uma vez tomada a decisão de migrar, a Internet, e principalmente as comunidades/grupos encontrados no Facebook, contribuem com informações que podem facilitar esse processo, uma vez que partem, maioritariamente, de nacionais do país de origem que já se encontram no país de destino. Estes já possuem acesso aos recursos locais e podem, posteriormente, auxiliar na sociabilidade dos estudantes que estão chegando, proporcionando-lhes encontros, festas, e outras formas de inserção na vida social do país de destino. Aí sim os estudantes irão se mobilizar dentro de comunidades/grupos via Facebook com o intuito de construírem uma vida social em Portugal. Desta maneira, estabelecem, num primeiro momento, laços fracos, valiosos para a coleta de informações e recursos (FAIST, 2010), mas que, no futuro, poderão se transformar em laços fortes, de partilha e convivência.

\section{REFERÊNCIAS:}

AURÉLIO, D. P. Liberdade de informação: órgãos de comunicação enfraquecem quando vão a jogo com as redes sociais. Público, 2016. Disponível em: $<$ https://www.publico.pt/politica/noticia/liberdade-de-informacao-orgaos-decomunicacao-perdem-quando-vao-a-jogo-com-as-redes-sociais-1719244>. Acesso em: 06/01/2016.

BROOKS, R.; WATERS, J. Social networks and educational mobility: the

\footnotetext{
${ }^{15}$ Nota nossa.
} 
experiences of UK students. Globalisation, Societies and Education, v. 8, n, 1, 2010, p. 143-157.

CASTELLS, S. Entendendo a migração global: uma perspetiva desde a transformação social. Revista Interdisciplinar de Mobilidade Humana, Brasília, ano XVIII, n. 35, p. 11-43, jul./dez. 2010.

COGO, D. Internet e redes migratórias transnacionais: narrativas da diáspora sobre o Brasil como país de imigração. Revista Novos Olhares, São Paulo, v. 4, n.1, 2014, p. 91-103.

DEKKER, R.; ENGBERSEN, G. How social media transform migrant networks and facilitate migration. Journal of Ethnic and Migration Studies, v.38, n. 9, p. 401418, novembro 2012.

DELICADO, A. Cientistas Portugueses no Estrangeiro. Fatores de mobilidade e relações de diáspora. Sociologia, Problemas e Práticas, Lisboa, n. 58, p. 109-129, 2008.

DE HAAS, H. The Internal Dynamics of Migration Processes: A Theoretical Inquiry. In the Journal of Ethnic and Migration Studies, v. 36, n. 10, p. 1587 - 1617, 2010.

FAIST, T. The crucial mesolevel. In: MARTINIELLO, M. \& RATH, J. Selected studies in international migration and immigrant incorporation. Amsterdam: Amsterdam University Press, 2010. p. 59-90.

GRANOVETTER. M. S. The strength of weak ties. American journal of sociology, v. 78, n. 6, p. 1360-1380, may, 1973.

MALHEIROS, J. M. Os brasileiros em Portugal - a síntese do que sabemos. In: MALHEIROS, J. M. (org.) Imigração brasileira em Portugal. Lisboa: ACIDI, 2007, p. 11-38.

MAZZA, D. A internacionalização dos processos formativos: a circulação de pessoas, saberes e práticas no campo das Ciências Humanas. In: ENCONTRO ANUAL DA ANPOCS, 32., 2008, Caxambu. Anais... Caxambu: ANPOCS, 2008, p. $1-30$.

OIARZABAL, P. J.; REIPS, U-D. Migration and Diaspora in the Age of Information and Communication Technologies. Journal of Ethnic and Migration Studies, v. 38, n. 9, p. 1333-1338, novembro 2012.

PAPACHARISSI, Z. The virtual sphere 2.0: The Internet, the public sphere, and beyond. In: Routledge handbookof internet politics, 2009, p. 230-245.

RIBEIRO, N. Liberdade de informação: Entrevista “Órgãos de comunicação enfraquecem quando vão a jogo com as redes sociais", Jornal Público, Portugal, Edição de 6 de janeiro de 2016. Informação disponível em: 
$<$ https://www.publico.pt/politica/noticia/liberdade-de-informacao-orgaos-decomunicacao-perdem-quando-vao-a-jogo-com-as-redes-sociais-1719244>. Acesso em: 06/01/2016.

ROCHA, F. Noções de imigração e cultura na era da globalização: o caso dos estudantes brasileiros da Universidade de Coimbra. Atas do $1^{\circ}$ Seminário de Estudos Sobre Imigração Brasileira na Europa. Barcelona: Universitat de Barcelona, 2010, p. 230-237.

RUZON, B. P. Filhos de Coimbra: uma história do ensino jurídico brasileiro. Jus Navigandi, Teresina, v. 10, n.1201, outubro 2006. Disponível em:

$<$ http://jus2.uol.com.br/doutrina/texto.asp?id=9039>. Acesso em: 15/10/2011.

SALT, J. International movements of the highly skilled. OECD Social, Employment and Migration Working Papers, Paris. n.3, 1997.Disponível em: $<$ http://dx.doi.org/10.1787/10441106506>. Acesso em: 12/08/2015.

VAN MEETEREN, M.; PEREIRA, S. The differential role of social networks Strategies and routes in Brazilian migration to Portugal and the Netherlands. 2013. IMI Working Papers Series, n. 66, 2013.

VIDEIRA, P. A mobilidade internacional dos cientistas: construções teóricas e respostas políticas. In: ARAÚJO, E.; et al. Para um debate sobre mobilidade e fuga de cérebros. Braga: Centro de Estudos de Comunicação e Sociedade, Universidade do Minho, 2013, p. 138 -162.

VERTOVEC, S. Transnational networks and skilled labour migration. 2002. Disponível em: $<$ http://163.1.0.34/working\%20papers/WPTC-0202\%20Vertovec.pdf>. Acesso em: 11/08/2015.

Recebido em: 27.10 .2016

Aceito em: 31.03 .2017 